\title{
Dietary intake and main food sources of vitamin D and calcium in Colombian urban adults
}

\author{
Mateo Amaya-Montoya ${ }^{1}$, Daniela Duarte-Montero', Luz D Nieves-Barreto ${ }^{1}$, Angélica Montaño-Rodríguez ${ }^{1}$, \\ Eddy C Betancourt-Villamizar², María P Salazar-Ocampo ${ }^{1}$ and Carlos O Mendivil(iD1,3 \\ ${ }^{1}$ School of Medicine, Universidad de los Andes, Bogotá, Colombia \\ ${ }^{2}$ Team Foods, Bogotá, Colombia \\ ${ }^{3}$ Fundación Santa Fe de Bogotá, Section of Endocrinology, Bogotá, Colombia
}

Correspondence should be addressed to C O Mendivil: cmendivi@uniandes.edu.co

This paper forms part of a special series on 100 Years of Vitamin D. The guest editors for this section were Josef Köhrle, Susan Lanham-New and Martina Rauner

\begin{abstract}
Data on dietary calcium and vitamin D intake from Latin America are scarce. We explored the main correlates and dietary sources of calcium and vitamin D in a probabilistic, population-based sample from Colombia. We studied 1554 participants aged 18-75 from five different geographical regions. Dietary intake was assessed by employing a 157-item semi-quantitative food frequency questionnaire and national and international food composition tables. Daily vitamin D intake decreased with increasing age, from 230 IU/day in the 18-39 age group to $184 \mathrm{IU} /$ day in the $60-75$ age group $(P$-trend $<0.001)$. Vitamin $D$ intake was positively associated with socioeconomic status (SES) (196 IU/day in lowest vS 234 in highest SES, $P$-trend < 0.001), and with educational level (176 IU/day in lowest vs 226 in highest education level, $P$-trend $<0.001)$. Daily calcium intake also decreased with age, from $1376 \mathrm{mg} /$ day in the $18-39$ age group to $1120 \mathrm{mg}$ /day in the 60-75 age group ( $P$-trend $<0.001)$. Calcium intake was lowest among participants with only elementary education, but the absolute difference in calcium intake between extreme education categories was smaller than for vitamin D (1107 vs $1274 \mathrm{mg} /$ day, $P$-trend $=0.023$ ). Daily calcium intake did not correlate with SES $(P$-trend $=0.74)$. Eggs were the main source of overall vitamin $D$, albeit their contribution decreased with increasing age. Dairy products contributed at least $48 \%$ of dietary calcium in all subgroups, mostly from cheese-containing traditional foods. SES and education were the key correlates of vitamin D and calcium intake. These findings may contribute to shape public health interventions in Latin American countries.
\end{abstract} Key Words

- calcium

- vitamin D

- dietary intake

- nutritional epidemiology

\section{Introduction}

Calcium and vitamin D represent two of the most important micronutrients involved in bone health and several other physiological processes. Calcium is almost entirely found in the mineral phase of the bone, while a small proportion resides in the extracellular fluid (1). This extracellular fraction is tightly controlled and regulates, among others, cell membrane integrity, muscle contraction, neuron excitability, and coagulation (1). Vitamin D on the other hand exerts an integrated hormonal control of calcium plasmatic concentration by modifying bone resorption and intestinal absorption (2). Both micronutrients are fundamental in various stages of bone metabolism across the lifespan. These include fetal bone mineralization, skeletal growth during childhood, reaching peak bone

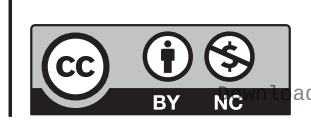

This work is licensed under a Creative Commons Attribution-NonCommercial 4.0 International License. ded from Bioscientifica.com at 04/26/2023 10:37:34AM 
mass, and continuous bone remodeling throughout adulthood $(3,4,5)$.

Several large, national surveys undertaken in Asia $(6,7)$, North America $(8,9,10)$, Europe $(11,12,13)$, and Oceania (14) have assessed calcium or vitamin D dietary intakes at the population level. In case of Latin America, information on this issue is quite limited, as most of the studies have been performed in non-representative samples with small size or restricted to a single sex or age group $(15,16)$. In Colombia, the last national survey of nutritional situation (ENSIN) 2015 did not assess the dietary intake of vitamin $\mathrm{D}$ (17). The information of vitamin D and calcium dietary intakes of Colombian population has not been assessed in any national survey.

Research has shown that diet quality has a positive relation with socioeconomic status (SES) (18, 19). Similarly, educational attainment has a strong effect in micronutrient intake, even greater than occupation and income $(20,21)$. As for calcium and vitamin D, several studies have also described relevant correlates and reported the main dietary sources of calcium and vitamin D (15). Aside from age and sex, SES, income, rural/urban setting, and self-reported race (not skin color) have shown associations with intake in different studies $(22,23)$. Acknowledging these factors is very important because they may help in identifying the groups that would benefit the most from public health interventions. On the other hand, identification of the main dietary sources is required for modeling the impact of fortification efforts, which is one of the recommended steps in the process of developing successful policies $(24,25)$.

Therefore, the main objective of this study was to compare the dietary intakes of vitamin $\mathrm{D}$ and calcium according to sex, age, SES, educational level, and location, in a probabilistic, population-based sample from the five most important cities in Colombia, South America.

\section{Materials and methods}

This study is a part of Estudio Colombiano de Perfiles Nutricionales - Colombian Study of Nutritional Profiles, a cross-sectional, population-based, multi-stage sampling dietary survey performed in five cities, each of which represents one of Colombia's major regions. The sampling frame was obtained from the last census of the Colombian population (2005), cartography was obtained from the national geostatistical frame developed by the Colombian National Department of Statistics (Departamento Administrativo Nacional de Estadística (DANE)) (26), and data on SES came from the National Superintendence of Public Services. In the first stage of sampling, we selected cartographic sectors, within sectors we selected blocks (on average eight per cartographic sector), within blocks we selected households, and within households we selected individual participants. All individuals over the age of 18 were listed and a person was randomly selected. The sample was stratified by city, sex, age group, and SES of the household.

All data were collected between June and November 2018. Information was captured using a tablet device containing digital forms with proper validation rules developed for the study. The staff in charge of data collection was extensively trained by the study principal investigator. With this design and including the design effect, the study sample yielded an overall sampling error of $2.2 \%$. The sampling errors for each city were Bogota 4.0\%, Medellin 5.0\%, Cali 5.0\%, Barranquilla 5.6\% and Bucaramanga $6.8 \%$, respectively.

\section{Participants}

Participants were individuals between the ages of 18 and 75 , residing in one of the five cities mentioned above. We excluded foreigners living in Colombia, individuals in hemodialysis or peritoneal dialysis therapy, and persons with disabilities that precluded a reliable fulfillment of the study questionnaire.

\section{Sociodemographic and anthropometric variables}

We collected information on sex, date of birth, household SES, marital status, individual educational level, and employment status using a standardized questionnaire. SES is classified in Colombia by the Statistics Department, DANE in six strata according to characteristics of the residence (with stratum 1 being the lowest and stratum 6 being the highest) (27). Residential dwellings are classified according to their physical characteristics and environment. The methodology for this classification creates homogeneous strata taking information about land use, public utilities, access routes, topography, land valuation, and property characteristics as the inputs. Given that sociodemographic, income, and human development indicators are more similar for individuals living in strata 4-6 than among the other strata (26), we analyzed SES in three groups, corresponding to strata 1-2 (low SES), 3 (medium SES), and 4-6 (high SES). Educational level was recorded as the highest educational cycle completed and was categorized as elementary or lower, high school,

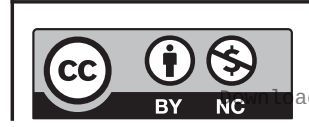


technical degree, and college or higher. Height was measured using a portable stadiometer supported on a firm surface. Weight was measured employing a solar digital scale with $100 \mathrm{~g}$ sensitivity and $200 \mathrm{~kg}$ capacity.

\section{Food frequency questionnaire}

Dietary intake was assessed using a previously developed semi-quantitative food frequency questionnaire (FFQ) with a 157-item food list (28). This list included foods eaten by no less than $30 \%$ of the Colombian population based on the results of the 2005 Survey of the Nutritional Situation of Colombia (ENSIN 2005). Food sources with a high content of vitamin D and calcium were thoughtfully represented as the list included 13 different dairy products, 9 kinds of fish, eggs, mushrooms among others. Participants reported the frequency of intake and the number of standard portions consumed (with reference portion size written next to this field). Frequency of intake was registered as one of the nine categories, that is never, one to three times per month, once a week, two to four times a week, five to six times a week, once a day, two to three times a day, four to six times a day, or more than six times a day. A trained staff member administered the FFQ and registered all the information. A supplemental album with images of the standard portions for each item was also available.

Estimation of daily nutrient intake was done as previously described (29). First, a weighing factor was used to convert each frequency of intake to number of portions consumed in a day. Then a factor was used to convert the number of portions a day to $100 \mathrm{~g}$ units. Subsequently, an edible fraction factor was applied. Composition data were obtained from the Colombian Institute of Family Welfare (Instituto Colombiano de Bienestar Familiar (ICBF)) reference tables (30). For foods not in ICBF tables, composition was extracted from Central America and Panama Nutrition Institute (Instituto de Nutrición de Centro América y Panamá) tables (31), or the U.S. Department of Agriculture food composition database (32). For foods not represented in any of these sources, information from the manufacturer was employed.

\section{Data analysis}

The daily and energy-adjusted intakes of calcium and vitamin D intakes were compared across categorical predictors (sex, age group, SES, education group, and city) using ANOVA. We also calculated the proportion of individuals with daily intakes below the estimated average requirement (EAR) for vitamin D (400 IU/day) and calcium ( $800 \mathrm{mg} /$ day). Post hoc analyses using the least squares difference (LSD) method were done when statistically significant differences were found in global ANOVA. Trend analysis of energy-adjusted nutrient intake across ordinal predictors (age, SES, and education groups) were done using linear regression of estimated marginal means. All analyses were two-tailed and carried out at a 5\% significance level. All analyses were performed in SPSS for Windows, v.21 (Cary, NC, USA).

\section{Ethical aspects}

Participants provided written informed consent and all study procedures were performed according to the principles of the Helsinki Declaration and to local rules and regulations as provided by Resolution 8430 of 1993 of the Colombian Ministry of Health. The study was approved by the Institutional Review Board of Universidad de los Andes (Comité de Ética de la Vicerrectoría de Investigaciones), according to minute 1016 of April 27, 2018.

\section{Results}

\section{Demographic and socioeconomic characteristics}

The study sample included 1554 adults, with equal representation from both sexes (Table 1). Almost half of the participants (42.2\%) were in the 18-39-year-old group, followed by the 40-59 (30.8\%) and 60-75 (27\%)-year-old groups. Average BMI of both men and women was in the overweight range. Bogota was the city with most participants recruited (31.7\%) and Bucaramanga the least (10.8\%).

\section{Correlates of dietary vitamin D intake}

The daily intake of vitamin $\mathrm{D}$ decreased with increasing age group in both sexes, from 230 IU/day in the 18-39 age group to $184 \mathrm{IU} /$ day in the $60-75$ age group $(P$-trend $<0.001$, Fig. 1A). However, calorie-adjusted vitamin $D$ intake showed no difference among categories $(P=0.33)$ nor linear trend $(P$-trend $=0.55)$ across age groups (Table 2 ). Statistically significant differences between men and women were seen within age groups. Daily vitamin D intake was higher among men in the 40-59 age group $(P<0.001)$. Energy-adjusted vitamin $\mathrm{D}$ intake was higher among women in the $18-39$ years group $(P=0.005)$ and higher among men in the 40-59 age group $(P=0.019)$ (Table 2). The overall proportion of participants not meeting the vitamin D EAR was $85.7 \%$ among men and 
Table 1 Study population's sociodemographic and anthropometric characteristics. Data are expressed as number of participants (percentage) or mean (S.D.). Socioeconomic status (SES) according to Colombia's official Statistics Department - DANE, where SES 1 and 2 were considered as low, SES 3 as medium, and SES 4-6 as high.

\begin{tabular}{|c|c|c|c|}
\hline & Male & Female & Total \\
\hline$n$ & $721(46.4)$ & $833(52.6)$ & 1554 \\
\hline \multicolumn{4}{|l|}{ Age group (years) } \\
\hline $18-39$ & $316(43.8)$ & 339 (40.7) & $655(42.2)$ \\
\hline $40-59$ & $210(29.1)$ & 269 (32.3) & $479(30.8)$ \\
\hline $60-75$ & $195(27.0)$ & $225(27.0)$ & $420(27.0)$ \\
\hline Weight (kg) & $74.3(15.1)$ & $67.4(13.2)$ & $70.6(14.6)$ \\
\hline Height (m) & $169.6(7.9)$ & $155.7(8.8)$ & $126.1(10.8)$ \\
\hline $\mathrm{BMI}\left(\mathrm{kg} / \mathrm{m}^{2}\right)$ & $25.8(4.6)$ & $28.1(8.7)$ & $26.9(7.2)$ \\
\hline \multicolumn{4}{|l|}{ Socioeconomic level } \\
\hline Low & 288 (39.9) & 356 (42.6) & 644 (41.4) \\
\hline Medium & $219(30.4)$ & 241 (28.9) & $460(29.6)$ \\
\hline High & 214 (29.7) & 28.3) & 450 (29.0) \\
\hline \multicolumn{4}{|l|}{ City } \\
\hline Barranquilla & $120(16.2)$ & $126(15.4)$ & 246 (15.8) \\
\hline Bogotá & 226 (31.3) & $267(32.0)$ & 493 (31.7) \\
\hline Bucaramanga & $71(9.8)$ & 97 (11.6) & $168(10.8)$ \\
\hline Cali & 145 & $172(20.7)$ & 317 (20.4) \\
\hline Medellín & $159(22.1)$ & $171(20.3)$ & $330(21.2)$ \\
\hline \multicolumn{4}{|l|}{ Educational levela } \\
\hline $\begin{array}{l}\text { Elementary or } \\
\text { lower }\end{array}$ & 142 (19.7) & $182(21.8)$ & $324(20.8)$ \\
\hline High school & 299 (41.5) & 332 (39.9) & $631(40.6)$ \\
\hline $\begin{array}{l}\text { Technical/ } \\
\text { associate degree }\end{array}$ & $130(18.0)$ & $156(18.7)$ & $286(18.4)$ \\
\hline College or higher & $150(20.8)$ & $163(19.6)$ & $313(20.1)$ \\
\hline
\end{tabular}

aHighest educational level achieved.

90\% among women; this proportion was highest among men aged 40-59 (Table 2).

Both daily vitamin D intake and calorie-adjusted vitamin $\mathrm{D}$ intake showed a significant positive trend across SES levels ( $P$-trend $<0.001$ in both cases). Daily vitamin D intake was significantly higher in the high SES compared to the low $(P<0.001)$, and medium $(P=0.013)$ SES categories (Fig. 1B). Daily vitamin D intake was higher among men relative to women only in the high SES (Table 2).

Likewise, educational attainment and daily vitamin D intake showed a positive linear relation $(P$-trend $=0.002)$. Persons with only elementary or lower education had significantly lower vitamin D intakes than all other educational categories (Fig. 1C). Having a college or higher educational degree was associated with significantly higher energy-adjusted vitamin D intake compared to individuals with only a technical/associated degree (estimated difference $13.4 \mathrm{IU} / 1000 \mathrm{kcal}, P=0.001$ ), high school (estimated difference 13.6 IU/1000 kcal, $P<0.001$ ), or elementary school or lower (estimated difference
$21.4 \mathrm{IU} / 1000 \mathrm{kcal}, P<0.001)$. There were no differences between men and women within each educational level group.

Barranquilla was the city with the lowest vitamin D intake, which differed significantly from all other cities. Women from Bucaramanga had lower daily vitamin D intakes than their male counterparts (Table 2).

\section{Correlates of dietary calcium intake}

Similar to vitamin D, the daily intake of calcium also decreased with increasing age group $(P$-trend $<0.001$, Fig. 2A), although the magnitude of the decrease between extreme age groups was larger among men (398 mg/day in men, $126 \mathrm{mg}$ /day in women). Consequently, daily calcium intake was significantly higher among men only in the 18-39 age group. The overall proportion of participants not meeting the calcium EAR was $31.3 \%$ among men and $37.6 \%$ among women; this proportion was highest in the 60-75 age group and among participants with only elementary or lower education (Table 3).

SES did not display an association with daily calcium intake (Fig. 2B). However, SES was positively associated with energy-adjusted calcium intake $(323 \mathrm{mg} / 1000 \mathrm{kcal}$ in lowest vs $372 \mathrm{mg} / 1000 \mathrm{kcal}$ in highest SES, $(P$-trend $<0.001)$. Like in the case of vitamin $\mathrm{D}$, daily calcium intake was higher among men relative to women only in the high SES (Table 2).

Even though the trend was less pronounced than for vitamin D, educational attainment showed a positive monotonic relation with calcium intake as well $(P$-trend $=0.023$, Fig. 2C). Participants of all other educational levels had significantly higher daily calcium intakes than those with only elementary or lower education. The trend was also present for energy-adjusted calcium intake (312 IU/1000 kcal in lowest vs $379 \mathrm{IU} / 1000 \mathrm{kcal}$ in highest education level, $P$-trend $<0.001$ ) (Table 3).

Barranquilla had the highest calcium intake among the studied cities. Within each city, there were no significant differences in daily calcium intake by sex (Table 3).

\section{Food sources of vitamin D}

Eggs as an individual food were the main dietary source of vitamin D in the complete sample (24.3\%) (Fig. 3). Consumption of vitamin D from fortified dairy and non-dairy drinks progressively increased with age, whereas the consumption of vitamin D from eggs and fortified 
A

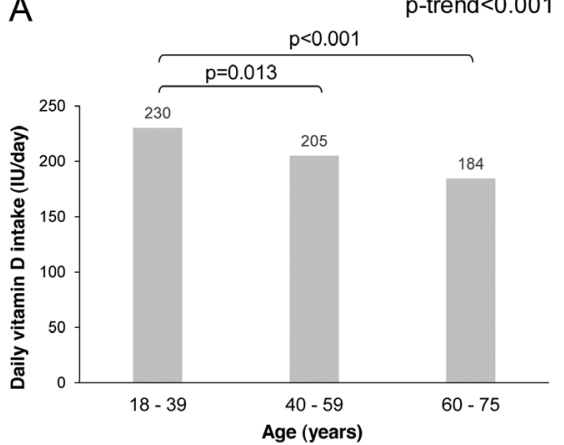

B

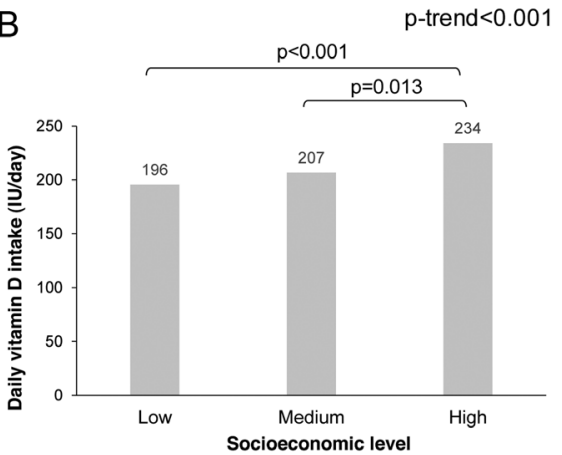

C

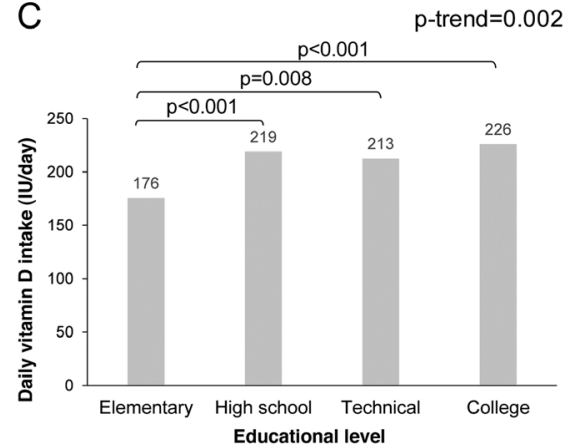

Figure 1

Daily vitamin D intake. (A) by age group; (B) by SES; (C) by educational level. Only significant between-category $P$-values are shown.

breakfast cereals decreased (Fig. 3A). Vitamin D intake from fortified dairy was similar across all SES levels, but intake from meats and fortified breakfast cereals was more common with increasing SES (Fig. 3B). Similarly, the proportion of vitamin D obtained from meats increased with education level, at the expense of vitamin D from eggs (Fig. 3C). Analyses by city showed a remarkable variability in vitamin D sources, especially non-dairy (1-13\%) and fortified dairy (21-36\%) drinks.

\section{Food sources of calcium}

Dairy products were consistently the main source of calcium, contributing with at least $48 \%$ in all age, SES, and education categories (Fig. 4). Within this food group, hard cheese contributed the most (12.9-22.1\%). Sources of calcium were similar among age and SES groups (Fig. 4A and B). The highest education group consumed
$8 \%$ more calcium from dairy and 5\% less calcium from non-dairy drinks than the lowest group (Fig. 4C). In Barranquilla, dairy products provided $66 \%$ of total calcium intake, mainly due to the contribution of hard cheese (39\% of all daily calcium). In Cali, traditional Colombian pastries were the first individual source of calcium (11.2\%).

\section{Discussion}

In this study, we report a population-based estimation of the current consumption and food sources of key nutrients for bone health among Colombian urban adults. The central results reflect that the intake of vitamin $\mathrm{D}$ and calcium of most Colombians is strongly influenced by SES and educational level. Individuals with low SES or limited education showed concerningly lower intakes and lower

Table 2 Daily and energy-adjusted vitamin D intake. Data are mean (S.D).

\begin{tabular}{|c|c|c|c|c|c|c|c|c|c|}
\hline \multirow[b]{2}{*}{ Variable } & \multirow[b]{2}{*}{ Category } & \multicolumn{2}{|c|}{ Daily intake (IU/day) } & \multirow{2}{*}{$\begin{array}{c}\text { P-value } \\
\text { between } \\
\text { sexes }\end{array}$} & \multicolumn{2}{|c|}{$\begin{array}{c}\text { Energy-adjusted } \\
\text { intake (IU/1000 kcal) }\end{array}$} & \multirow{2}{*}{$\begin{array}{c}\text { P-value } \\
\text { between } \\
\text { sexes } \\
\end{array}$} & \multicolumn{2}{|c|}{ \% below EAR } \\
\hline & & Men & Women & & Men & Women & & Men & Women \\
\hline \multirow[t]{3}{*}{ Age group } & $18-39$ & $240(184)$ & $222(170)$ & 0.19 & $54(37)$ & $61(42)$ & 0.005 & 82.9 & 88.2 \\
\hline & $40-59$ & $238(187)$ & $179(146)$ & $<0.001$ & $64(49)$ & $58(38)$ & 0.019 & 83.3 & 91.8 \\
\hline & $60-75$ & $177(132)$ & $191(186)$ & 0.40 & $61(46)$ & $62(46)$ & 0.81 & 92.8 & 90.7 \\
\hline \multirow[t]{3}{*}{ SES } & Low & 209 (183) & 185 (166) & 0.08 & $51(37)$ & $53(40)$ & 0.41 & 87.5 & 91.3 \\
\hline & Medium & 206 (155) & 207 (163) & 0.94 & $58(46)$ & 59 (49) & 0.50 & 89.0 & 88.4 \\
\hline & High & $256(178)$ & $214(175)$ & 0.011 & $71(46)$ & $72(43)$ & 0.93 & 79.9 & 89.8 \\
\hline \multirow[t]{4}{*}{ Education } & Elementary or lower & 189 (175) & $166(162)$ & 0.22 & $49(38)$ & $52(38)$ & 0.46 & 90.8 & 90.7 \\
\hline & High School & $231(186)$ & $208(184)$ & 0.13 & $58(40)$ & $59(43)$ & 0.64 & 83.6 & 89.8 \\
\hline & Technical/Associate degree & $216(156)$ & $210(155)$ & 0.75 & $57(41)$ & $60(37)$ & 0.36 & 90.0 & 89.7 \\
\hline & College or higher & $244(161)$ & $210(147)$ & 0.056 & $72(52)$ & $72(45)$ & 0.64 & 81.3 & 90.2 \\
\hline \multirow[t]{5}{*}{ City } & Barranquilla & $163(133)$ & $180(139)$ & 0.32 & $41(29)$ & $52(34)$ & 0.004 & 95.8 & 92.9 \\
\hline & Bogota & $239(183)$ & $212(186)$ & 0.11 & $66(48)$ & $64(44)$ & 0.51 & 84.1 & 88.4 \\
\hline & Bucaramanga & $217(163)$ & $156(142)$ & 0.01 & $64(41)$ & $52(39)$ & 0.009 & 85.9 & 97.9 \\
\hline & Cali & 209 (175) & $182(144)$ & 0.14 & $58(43)$ & $58(43)$ & 0.93 & 87.6 & 94.2 \\
\hline & Medellin & 259 (183) & 237 (185) & 0.28 & $62(43)$ & $66(42)$ & 0.15 & 78.6 & 81.9 \\
\hline All & & 222 (187) & 200 (168) & 0.009 & $62(43)$ & $60(42)$ & 0.62 & 85.7 & 90.0 \\
\hline
\end{tabular}

EAR, estimated average requirement (daily intake of 400 IU/day); SES, socioeconomic status.

https://ec.bioscientifica.com

https://doi.org/10.1530/EC-21-0341 (c) 2021 The authors Published by Bioscientifica Ltd

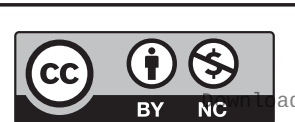

This work is licensed under a Creative Commons Attribution-NonCommercial 4.0 International License. ded from Bioscientifica.com at 04/26/2023 10:37:34AM via free access 
A

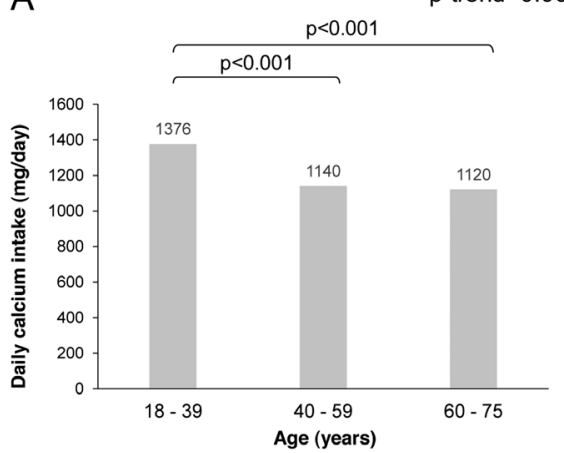

B

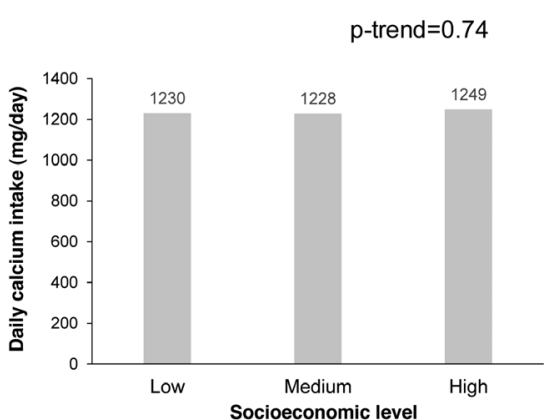

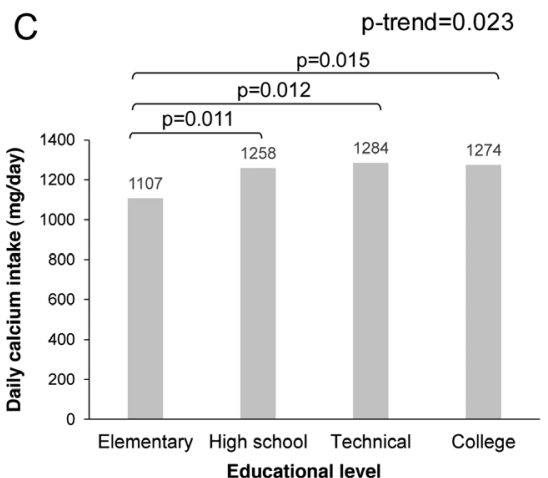

Figure 2

Daily calcium intake. (A) by age group; (B) by SES; (C) by educational level. The overall difference among groups was significant $(P<0.001)$. Only significant between-category $P$-values are shown.

percentages of achievement of the EAR. Colombia has been classified as one of the countries with the highest income inequality in the world (33). Due to the structure of the educational system, this difference in income is at least partially paralleled by differences in educational attainment (34), favoring the wealthiest or more educated individuals in many health-related outcomes. Examples of this include mortality from cardiovascular diseases (35), cancer (36), and diabetes (37).

Similar results have been documented in the US. A joint cross-sectional analysis of data from three versions of the National Health and Nutrition Examination Survey found that inadequate intake of vitamin D was more prevalent among people living in households whose earnings were less than 20,000 dollars per year (38). As for calcium, individuals aged 50 and older living below the poverty line presented a higher prevalence of inadequate intake.

In terms of dietary sources, it was previously known that Colombians with low SES consume fewer fruits and vegetables (39), while high SES households consume more dairy products and sweets (40). In contrast, we found a similar consumption of vitamin D from dairy products in different SES and educational groups. This finding suggests that the marked difference in vitamin D intake observed among these categories was mainly due to a higher contribution from fish and meat in the diet. Further analysis revealed that higher SES and education individuals consumed more vitamin D-rich meats. For instance, salmon provided $8.3 \%$ of the total daily vitamin D intake in the high SES and $8.8 \%$ in the high education category. On the other hand, salmon provided only $1.9 \%$

Table 3 Daily and energy-adjusted calcium intake. Data are mean (S.D).

\begin{tabular}{|c|c|c|c|c|}
\hline \multirow[b]{2}{*}{ Variable } & \multirow[b]{2}{*}{ Category } & \multicolumn{2}{|c|}{ Daily Intake (mg/day) } & \multirow{2}{*}{$\begin{array}{c}\text { P-value } \\
\text { between } \\
\text { sexes }\end{array}$} \\
\hline & & Men & Women & \\
\hline \multirow[t]{3}{*}{ Age group } & $18-39$ & $1486(1019)$ & $1274(845)$ & 0.004 \\
\hline & $40-59$ & $1192(794)$ & $1100(822)$ & 0.22 \\
\hline & $60-75$ & $1088(737)$ & $1148(932)$ & 0.44 \\
\hline \multirow[t]{3}{*}{ SES } & Low & $1281(900)$ & $1188(894)$ & 0.19 \\
\hline & Medium & $1258(953)$ & $1200(719)$ & 0.46 \\
\hline & High & $1346(854)$ & $1161(861)$ & 0.023 \\
\hline \multirow[t]{4}{*}{ Education } & Elementary school or lower & $1144(905)$ & 1078 (847) & 0.50 \\
\hline & High School & $1311(879)$ & $1210(845)$ & 0.14 \\
\hline & Technical/Associate degree & $1339(910)$ & $1238(794)$ & 0.32 \\
\hline & College or higher & 1358 (932) & $1197(846)$ & 0.11 \\
\hline \multirow[t]{5}{*}{ City } & Barranquilla & $1570(1017)$ & $1525(1036)$ & 0.73 \\
\hline & Bogota & $1245(990)$ & $1136(819)$ & 0.18 \\
\hline & Bucaramanga & $1034(655)$ & 966 (849) & 0.58 \\
\hline & Cali & $1170(794)$ & $1053(656)$ & 0.15 \\
\hline & Medellin & $1380(811)$ & $1263(778)$ & 0.18 \\
\hline All & & $1293(903)$ & 1184 (837) & 0.013 \\
\hline
\end{tabular}

\begin{tabular}{|c|c|}
\hline \multicolumn{2}{|c|}{$\begin{array}{l}\text { Energy-adjusted intake } \\
\qquad(\mathrm{mg} / 1000 \mathrm{kcal})\end{array}$} \\
\hline Men & Women \\
\hline 327 (160) & 340 (181) \\
\hline 308 (136) & 345 (189) \\
\hline 344 (179) & 372 (194) \\
\hline 307 (141) & 336 (188) \\
\hline 321 (150) & 336 (149) \\
\hline 358 (186) & 385 (216) \\
\hline 286 (128) & 332 (182) \\
\hline 323 (156) & 341 (181) \\
\hline 325 (150) & 352 (189) \\
\hline 372 (188) & 386 (200) \\
\hline 381 (170) & 433 (242) \\
\hline 318 (159) & 344 (190) \\
\hline 303 (140) & 306 (178) \\
\hline 319 (176) & 328 (160) \\
\hline 313 (134) & 344 (149) \\
\hline 326 (159) & 380 (187) \\
\hline
\end{tabular}

\begin{tabular}{|c|c|c|}
\hline \multirow{2}{*}{$\begin{array}{c}\text { P-value } \\
\text { between } \\
\text { sexes }\end{array}$} & \multicolumn{2}{|c|}{ \% below EAR } \\
\hline & Men & Women \\
\hline 0.21 & 24.1 & 31.9 \\
\hline 0.001 & 32.9 & 41.6 \\
\hline 0.023 & 41.5 & 41.3 \\
\hline 0.003 & 34.0 & 40.2 \\
\hline 0.19 & 34.2 & 32.0 \\
\hline 0.019 & 24.8 & 39.4 \\
\hline 0.001 & 43.7 & 44.5 \\
\hline 0.06 & 31.4 & 36.4 \\
\hline 0.07 & 30.8 & 33.3 \\
\hline 0.31 & 20.0 & 36.2 \\
\hline 0.001 & 20.0 & 23.8 \\
\hline 0.021 & 30.5 & 40.8 \\
\hline 0.86 & 46.5 & 46.4 \\
\hline 0.51 & 37.9 & 43.0 \\
\hline 0.021 & 28.3 & 32.2 \\
\hline 0.008 & 31.3 & 37.6 \\
\hline
\end{tabular}

EAR, estimated average requirement (daily intake of $800 \mathrm{mg} /$ day); SES, socioeconomic status.

https://ec.bioscientifica.com

https://doi.org/10.1530/EC-21-0341 (c) 2021 The authors Published by Bioscientifica Ltd

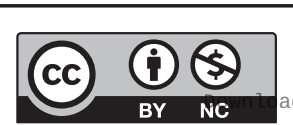

This work is licensed under a Creative Commons Attribution-NonCommercial 4.0 International License. ded from Bioscientifica.com at 04/26/2023 10:37:34AM via free access 
A $100 \%$

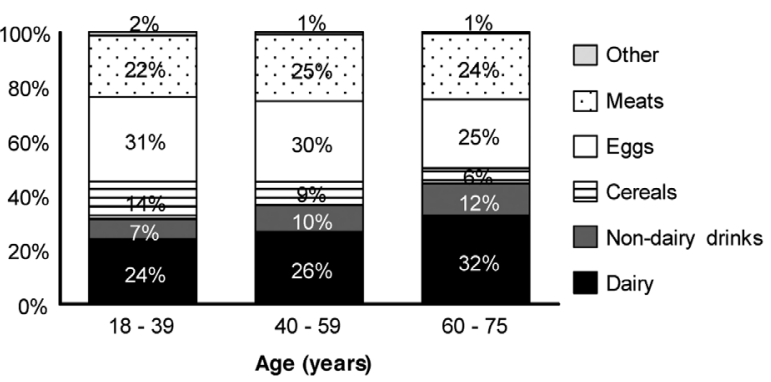

B
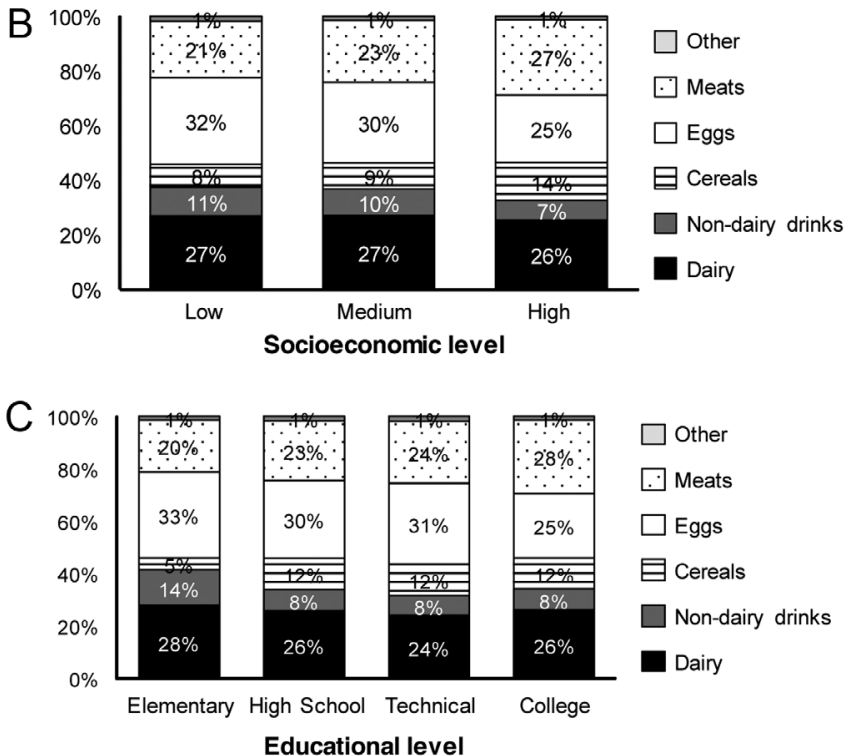

Figure 3

Food sources of vitamin D by age (A), SES (B), and educational level (C). Cereals refers to fortified breakfast cereals. Dairy includes fortified milk.

of vitamin D in the low SES and 1.8\% in the low education groups. Despite these differences, the main food sources of vitamin D in the whole sample were dairy products (37.6\%) and eggs (24.3\%), similar to prior findings from the Czech Republic (41) and Canada (9). By contrast, in Spain, Australia, and South Korea, fish, meats, and eggs were the main contributors $(7,13,14)$.

Our findings are in line with most reports of calcium food sources from other countries, but some differences do exist, perhaps associated with cultural, geographic, or economic factors. Similar to Spain (13), Germany (42), and Canada (8), we found milk and dairy products to be the main sources of calcium in Colombia. In Asia, the scenario is quite different; vegetables, fish/shellfish, and cabbage are the main sources of calcium in China (6), Philippines (43), and South Korea (44).

We were surprised to find that the increase in calcium consumption with higher education was much more marked among men than women. One plausible hypothesis is that social roles prevalent in population segments with only an elementary education may discourage the consumption of dairy products among adult males. A study in China found that males with low education level and economic deprivation have poor knowledge about the nutritional value of dairy products (45). These individuals were more likely to have a lower intake of dairy products and an insufficient intake of calcium (45). We found the highest calcium intake in Barranquilla, the main city of the Northern Atlantic coast of Colombia. In this region, it is common for people to eat hard cheese ('queso costeño') as a side dish with multiple foods. This habit may explain to a large extent their leading position for calcium intake among cities. On the flip side, Barranquilla also had the lowest vitamin D intake, possibly because the increased hard cheese consumption comes at the expense of lower milk consumption, and the vitamin D content of hard cheese is rather low (19 IU/100 g).
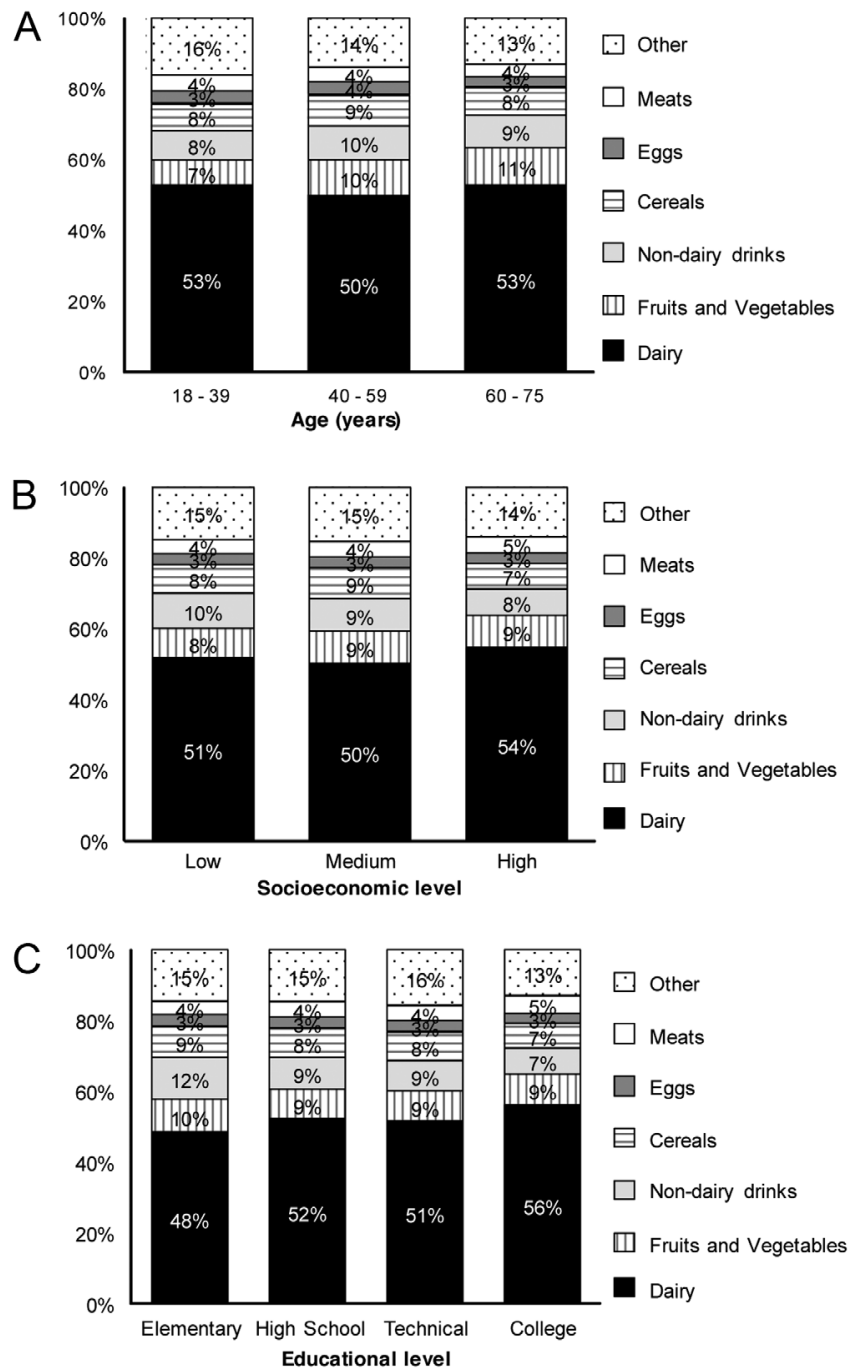

Figure 4

Food sources of calcium by age (A), SES (B), and educational level (C). Cereals refers to fortified breakfast cereals. Dairy includes fortified milk.

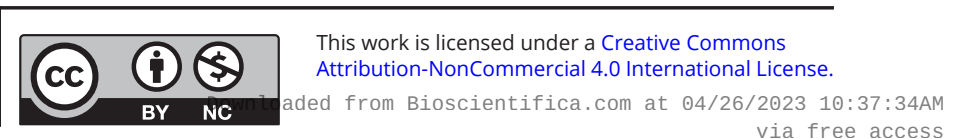


Cheese is a great source of calcium from the nutritional viewpoint; however, it can be very expensive in urban environments. This could explain why people with high SES and higher education consumed more dairy products and showed the highest calcium intake. Among the lowest SES and educational segments, we found a greater intake of non-dairy products, the main of which is 'agua de panela'. Agua de panela is a sweet typical Colombian beverage, made by suspending panela, a solidified block made from sugar cane juice in water. During the elaboration of panela, sugar cane juice is added with calcium hydroxide, in order to avoid the hydrolysis of sucrose and to improve the hardness and portability of the product (46). Therefore, agua de panela is an important source of calcium for low SES segments of the Colombian population.

This study has several strengths associated with its design. First, a probabilistic, population-based sample allows us to have more accurate and realistic estimations of nutritional data. Second, semi-quantitative FFQs are considered better for evaluating usual intake over long periods of time than other approaches like a single 24-h recall or food diaries (47). Third, we presented both daily intakes and energy-adjusted intakes in the analysis, in order to explore the association of both total intake and nutrient density with the sociodemographic factors of interest. Lastly, each of the cities incorporated represents a different cultural and geographic region, leading to the inclusion of distinct dietary patterns and food choices from the Colombian population. The main limitations were the lack of information about supplementary sources and from rural areas. Analyses involving use of supplements were challenging, as they were assessed in an open-ended fashion and many participants remembered only the brand and provided incomplete information about frequency and dose. Another limitation is that FFQs are not the best tool to estimate absolute intakes, therefore we focused mostly on internal comparisons and trends.

The results of this study reveal sociodemographic factors associated with a lower vitamin $\mathrm{D}$ and calcium intake in urban Colombia, serving as a framework for other Latin American and Caribbean countries with similar populations. These results complement and contextualize studies on vitamin D plasma concentrations (48) as tools to inform the development of feasible and effective dietary interventions. Based on our and prior results, efforts should be targeted to groups at high risk of inadequacy or its consequences, such as the older, postmenopausal women, and persons with low SES or educational attainment. Such efforts will be most successful if they are aimed at increasing consumption or at fortification of dairy products and eggs. There have been attempts at building a roadmap for the development of vitamin D fortification strategies (25).

In summary, we were able to identify SES level and education as very strong correlates of vitamin $\mathrm{D}$ and calcium intake. We also identified the main dietary sources of these nutrients in urban Colombia. These findings may contribute in shaping public health interventions not just in Colombia, but in other countries with a similar demographic and cultural background. Future studies that incorporate rural data, and that estimate absolute intakes including supplements, would expand on these relevant findings.

\section{Declaration of interest}

Even though this study was funded by Team Foods Colombia, it was executed independently by the study authors. The sponsoring company had no incidence on data analysis, on the contents of the manuscript, or on the decision to publish.

\section{Funding}

This study was funded by Team Foods Colombia.

\section{Author contribution statement}

All authors made substantial contributions to conception and design, acquisition of data, or analysis and interpretation of data; took part in drafting the article or revising it critically for important intellectual content; gave final approval of the version to be published; and agree to be accountable for all aspects of the work.

\section{Acknowledgements}

The authors thank Vicerrectoría de Investigaciones (Office for Research) of Universidad de los Andes for their continued support throughout the development of this project.

\section{References}

1 Goltzman D, Mannstadt M \& Marcocci C. Physiology of the calciumparathyroid hormone-vitamin D axis. Frontiers of Hormone Research 201850 1-13. (https://doi.org/10.1159/000486060)

2 Pike JW \& Christakos S. Biology and mechanisms of action of the vitamin D hormone. Endocrinology and Metabolism Clinics of North America 201746 815-843. (https://doi.org/10.1016/j.ecl.2017.07.001)

3 Urrutia-Pereira M \& Solé D. Vitamin D deficiency in pregnancy and its impact on the fetus, the newborn and in childhood. Revista Paulista de Pediatria 201533 104-113. (https://doi.org/10.1016/j. rpped.2014.05.004)

4 Heaney RP, Abrams S, Dawson-Hughes B, Looker A, Marcus R, Matkovic V \& Weaver C. Peak bone mass. Osteoporosis International 200011 985-1009. (https://doi.org/10.1007/s001980070020)

5 Hadjidakis DJ \& Androulakis II. Bone remodeling. Annals of the New York Academy of Sciences 20061092 385-396. (https://doi.org/10.1196/ annals.1365.035)

6 Huang F, Wang Z, Zhang J, Du W, Su C, Jiang H, Jia X, Ouyang Y, Wang Y, Li L, et al. Dietary calcium intake and food sources among 
Chinese adults in CNTCS. PLoS ONE 201813 e0205045. (https://doi org/10.1371/journal.pone.0205045)

7 Yoo K, Cho J \& Ly S. Vitamin D intake and serum 25-hydroxyvitamin D levels in Korean adults: analysis of the 2009 Korea National Health and Nutrition Examination Survey (KNHANES IV-3) using a newly established vitamin D database. Nutrients 20168 e610. (https://doi. org/10.3390/nu8100610)

8 Vatanparast H, Islam N, Patil RP, Shafiee M \& Whiting SJ. Calcium intake from food and supplemental sources decreased in the Canadian population from 2004 to 2015. Journal of Nutrition 2020150 833-841. (https://doi.org/10.1093/jn/nxz318)

9 Vatanparast H, Patil RP, Islam N, Shafiee M \& Whiting SJ. Vitamin D intake from supplemental sources but not from food sources has increased in the Canadian population over time. Journal of Nutrition 2020150 526-535. (https://doi.org/10.1093/jn/nxz291)

10 Quann EE, Fulgoni 3rd VL \& Auestad N. Consuming the daily recommended amounts of dairy products would reduce the prevalence of inadequate micronutrient intakes in the United States: diet modeling study based on NHANES 2007-2010. Nutrition Journal 201514 90. (https://doi.org/10.1186/s12937-015-0057-5)

11 Roman Viñas B, Ribas Barba L, Ngo J, Gurinovic M, Novakovic R, Cavelaars A, de Groot LC, van’t Veer P, Matthys C \& Serra Majem L. Projected prevalence of inadequate nutrient intakes in Europe. Annals of Nutrition and Metabolism 201159 84-95. (https://doi. org/10.1159/000332762)

12 Mensink GB, Fletcher R, Gurinovic M, Huybrechts I, Lafay L, Serra-Majem L, Szponar L, Tetens I, Verkaik-Kloosterman J, Baka A, et al. Mapping low intake of micronutrients across Europe. British Journal of Nutrition 2013110 755-773. (https://doi.org/10.1017/ S000711451200565X)

13 Olza J, Aranceta-Bartrina J, González-Gross M, Ortega RM, SerraMajem L, Varela-Moreiras G \& Gil Á. Reported dietary intake, disparity between the reported consumption and the level needed for adequacy and food sources of calcium, phosphorus, magnesium and vitamin D in the Spanish population: findings from the ANIBES Study. Nutrients 20179 e168. (https://doi.org/10.3390/nu9020168)

14 Jayaratne N, Hughes MC, Ibiebele TI, van den Akker S \& van der Pols JC. Vitamin D intake in Australian adults and the modeled effects of milk and breakfast cereal fortification. Nutrition 201329 1048-1053. (https://doi.org/10.1016/j.nut.2013.02.011)

15 Balk EM, Adam GP, Langberg VN, Earley A, Clark P, Ebeling PR, Mithal A, Rizzoli R, Zerbini CAF, Pierroz DD, et al. Global dietary calcium intake among adults: a systematic review. Osteoporosis International 201728 3315-3324. (https://doi.org/10.1007/s00198-017-4230-x)

16 Brito A, Cori H, Olivares M, Mujica MF, Cediel G \& López de Romaña D. Less than adequate vitamin D status and intake in Latin America and the Caribbean: a problem of unknown magnitude. Food and Nutrition Bulletin 201334 52-64. (https://doi. org/10.1177/156482651303400107)

17 Ministerio de Salud y Protección Social, Departamento Administrativo para la Prosperidad Social, Instituto Colombiano de Bienestar Familiar $\&$ Instituto Nacional de Salud. Encuesta Nacional de la Situación Nutricional, 2015. (available at: https://www.minsalud.gov.co/sites/r id/Lists/BibliotecaDigital/RIDE/VS/ED/GCFI/libro-ensin-2015.pdf)

18 Darmon N \& Drewnowski A. Does social class predict diet quality? American Journal of Clinical Nutrition 200887 1107-1117. (https://doi. org/10.1093/ajcn/87.5.1107)

19 Murayama N. Effects of socioeconomic status on nutrition in Asia and future nutrition policy studies. Journal of Nutritional Science and Vitaminology 201561 (Supplement) S66-S68. (https://doi.org/10.3177/ jnsv.61.S66)

20 Novaković R, Cavelaars A, Geelen A, Nikolić M, Altaba II, Viñas BR, Ngo J, Golsorkhi M, Medina MW, Brzozowska A, et al. Socio-economic determinants of micronutrient intake and status in Europe: a systematic review. Public Health Nutrition 201417 1031-1045. (https:// doi.org/10.1017/S1368980013001341)
21 Cembranel F, Wagner KJP, González-Chica DA \& d'Orsi E. Education and income levels are associated with energy and micronutrient intake. International Journal for Vitamin and Nutrition Research 202090 228-238. (https://doi.org/10.1024/0300-9831/a000535)

22 Moore CE, Radcliffe JD \& Liu Y. Vitamin D intakes of adults differ by income, gender and race/ethnicity in the U.S.A., 2007 to 2010. Public Health Nutrition 201417 756-763. (https://doi.org/10.1017/ S1368980013002929)

23 Malek AM, Newman JC, Hunt KJ \& Marriott BP. Race/ethnicity, enrichment/fortification, and dietary supplementation in the U.S. population, NHANES 2009-2012. Nutrients 201911 E1005. (https:// doi.org/10.3390/nu11051005)

24 Pilz S, März W, Cashman KD, Kiely ME, Whiting SJ, Holick MF, Grant WB, Pludowski P, Hiligsmann M, Trummer C, et al. Rationale and plan for vitamin $\mathrm{D}$ food fortification: a review and guidance paper. Frontiers in Endocrinology 20189 373. (https://doi.org/10.3389/ fendo.2018.00373)

25 Jääskeläinen T, Itkonen ST, Lundqvist A, Erkkola M, Koskela T, Lakkala K, Dowling KG, Hull GL, Kröger H, Karppinen J, et al. The positive impact of general vitamin $\mathrm{D}$ food fortification policy on vitamin D status in a representative adult Finnish population: evidence from an 11-y follow-up based on standardized 25-hydroxyvitamin D data. American Journal of Clinical Nutrition 2017 105 1512-1520. (https://doi.org/10.3945/ajcn.116.151415)

26 Departamento Administrativo Nacional de Estadística. Metodología de estratificación socioeconómica urbana para servicios públicos domiciliarios. Bogotá, Colombia: DANE, 2015. (available at: https:// www.dane.gov.co/files/geoestadistica/estratificacion/ManualdeR ealizacion.pdf)

27 Bushnell D \& Hudson RA. Social strata division. In Colombia: A Country Study, 5th ed., pp. 101-103. Ed RA Hudson. Washington, DC, USA: Federal Research Division, Library of Congress, 2010.

28 Monsalve Álvarez JM \& González Zapata LI. Development of a questionnaire to assess food intake in the University of Antioquia, Colombia. Nutricion Hospitalaria 201126 1333-1344. (https://doi. org/10.1590/S0212-16112011000600021)

29 Willett W. Reproducibility and validity of food frequency questionnaires. In Nutritional Epidemiology, 3rd ed., chapter 6, pp. 96-141. Oxford, UK: Oxford University Press, 2013.

30 Instituto Colombiano de Bienestar Familiar. Caracterización y composición nutricional de 18 preparaciones tradicionales en la población colombiana, 2017. (available at: https://www.icbf.gov.co/s ites/default/files/caracterizacion-composicion-18-preparaciones-tradic ionales-icbf1_0.pdf)

31 Instituto de Nutrición de Centro América y Panamá (INCAP). Tabla de composición de alimentos de Centro América, 2012. (available at: http://www.incap.int/mesocaribefoods/dmdocuments/TablaCAlime ntos.pdf)

32 U.S Department of Agriculture. Food Data Central. (available at: https://fdc.nal.usda.gov/)

33 Alvaredo F \& Gasparini L. Recent trends in inequality and poverty in developing countries. In Handbook of Income Distribution, Vol. 2, chapter 9, pp. 697-805. Amsterdam, Netherlands: Elsevier, 2015.(https://doi.org/10.1016/B978-0-444-59428-0.00010-2)

34 OECD. School education in Colombia. In OECD Reviews of School Resources: Colombia 2018 . Paris, France: OECD Publishing, 2018 (https://doi.org/10.1787/9789264303751-5-en)

35 Jimenez M \& Arroyave I. How educational inequalities in cardiovascular mortality evolve while healthcare insurance coverage grows: Colombia, 1998 to 2015. Value in Health Regional Issues 202023 112-121. (https://doi.org/10.1016/j.vhri.2020.08.001)

36 de Vries E, Arroyave I \& Pardo C. Time trends in educational inequalities in cancer mortality in Colombia, 1998-2012. BMJ Open 20166 e008985. (https://doi.org/10.1136/bmjopen-2015-008985)

37 Giraldo-Castrillon Y, Palacios-Barahona U \& Arroyave I. Time trends of diabetes in Colombia from 1998 to 2015: the recent stagnation in https://ec.bioscientifica.com https://doi.org/10.1530/EC-21-0341 (c) 2021 The authors Published by Bioscientifica Ltd

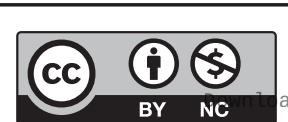

This work is licensed under a Creative Commons Attribution-NonCommercial 4.0 International License. ded from Bioscientifica.com at 04/26/2023 10:37:34AM 
mortality, and educational inequities. Primary Care Diabetes 202115 138-144. (https://doi.org/10.1016/j.pcd.2020.08.003)

38 Marshall K, Teo L, Shanahan C, Legette L \& Mitmesser SH. Inadequate calcium and vitamin D intake and osteoporosis risk in older Americans living in poverty with food insecurities. PLoS ONE 202015 e0235042. (https://doi.org/10.1371/journal.pone.0235042)

39 Herran OF, Patiño GA \& Gamboa EM. Socioeconomic inequalities in the consumption of fruits and vegetables: Colombian National Nutrition Survey, 2010. Cadernos de Saúde Pública 201935 e00031418. (https://doi.org/10.1590/0102-311X00031418)

40 González Zapata LI, Restrepo Mesa SL, Mancilla López L, Sepúlveda Herrera D \& Estrada Restrepo A. Inequalities in food consumption the Colombian households: results from the National Survey of Nutritional Status. Hacia la Promoción de la Salud 202126 98-117. (https://doi.org/10.17151/hpsal.2021.26.1.9)

41 Bischofova S, Dofkova M, Blahova J, Kavrik R, Nevrla J, Rehurkova I \& Ruprich J. Dietary intake of vitamin D in the Czech population: a comparison with dietary reference values, main food sources identified by a total diet study. Nutrients 201810 1452. (https://doi. org/10.3390/nu10101452)

42 Trautvetter U, Ditscheid B, Jahreis G \& Glei M. Habitual intakes, food sources and excretions of phosphorus and calcium in three German study collectives. Nutrients 201810 171. (https://doi.org/10.3390/ nu10020171)
43 Angeles-Agdeppa I, Sun Y, Denney L, Tanda KV, Octavio RAD, Carriquiry A \& Capanzana MV. Food sources, energy and nutrient intakes of adults: 2013 Philippines National Nutrition Survey. Nutrition Journal 201918 59. (https://doi.org/10.1186/s12937-019-0481-z)

44 Kim JM \& Bae YJ. Mineral intake status of community-dwelling elderly from urban and rural areas of South Korea: a cross-sectional study based on Korean National Health and Nutrition Examination Survey, 2013-2016. International Journal of Environmental Research and Public Health 202017 E3415. (https://doi.org/10.3390/ijerph17103415)

45 Zhao A, Szeto IMY, Wang Y, Li C, Pan M, Li T, Wang P \& Zhang Y. Knowledge, attitude, and practice (KAP) of dairy products in Chinese urban population and the effects on dairy intake quality. Nutrients 20179 668. (https://doi.org/10.3390/nu9070668)

46 Castro N, Gil N \& Bernal H. Manual de elaboración de panela y otros derivados de la caña. In Convenio de investigacion y divulgacion para el mejoramiento de la industria panelera. Barbosa, Colombia: CIMPA, 1992.

47 Biró G, Hulshof KF, Ovesen L, Amorim Cruz JA \& EFCOSUM Group. Selection of methodology to assess food intake. European Journal of Clinical Nutrition 200256 (Supplement 2) S25-S32. (https://doi. org/10.1038/sj.ejcn.1601426)

48 Hernando VU, Andry MM, María Virginia PF \& Valentina A. Vitamin D nutritional status in the adult population in Colombia - an analytical cross-sectional study. Heliyon 20206 e03479. (https://doi. org/10.1016/j.heliyon.2020.e03479)

Received in final form 26 October 2021

Accepted 12 November 2021

Accepted Manuscript published online 12 November 2021
This work is licensed under a Creative Commons Attribution-NonCommercial 4.0 International License. ded from Bioscientifica.com at 04/26/2023 10:37:34AM 